\title{
Mimarlıkta Akıllı Malzeme
}

\author{
Ahmet Selçuk TOPAL ${ }^{1 *} \odot$, Ümit ARPACIOĞLU \\ ${ }^{1}$ Mimar Sinan Güzel Sanatlar Üniversitesi, Fen Bilimleri Enstitüsü, Yapı Fiziği ve Malzeme Ana Bilim Dalı, 34427, \\ istanbul, Türkiye. \\ ${ }^{2}$ Mimar Sinan Güzel Sanatlar Üniversitesi, Mimarlık Fakültesi, Yapı Fiziği ve Malzeme Ana Bilim Dalı, 34427, \\ istanbul, Türkiye. \\ *e-mail: 20202101010@ogr.msgsu.edu.tr \\ Öz
}

Akıllı malzemeler alanı yirminci yüzyılda büyük bir gelişim yaşamıştır, yirmi birinci yüzyılın başlamasıyla beraber gelişme hızını daha da artırmıştır. Bu, mimarinin kendisinin gelişimine giden yolu açmıştır, tasarımcıların ve inşaat profesyonellerinin düşünme biçimini yeniden şekillendirmiştir. Akıllı malzeme kullanımının mimarlık uygulamalarında gittikçe daha fazla gelişmesi ve entegre olması, sadece bir uygulama olarak değil, tasarım sürecinin ilk aşamalarında da dikkate alınmasının gerekli olduğu açıklığa kavuşmaktadır. Araştırma, akıllı malzeme sistemlerinin mimarlık alanındaki özelliklerini ve avantajlarını araştırmayı, daha iyi uyarlanabilir özelliklere sahip mimari yaratmanın yolunu araştırmayı ve nihayetinde yapısal, iklimsel ve mimari performanslara kafa yoran kullanıcılar için en uygun ortamı sağlayarak "adapte edilebilirlik durumuna" ulaşmayı amaçlamaktadır. Mimarlık alanındaki araştırmacılar olarak, akıllı malzeme sistem teknolojilerini daha iyi anlayarak, mimari geliştirilebilir ve yenilik dönemine ulaşabilir.

Anahtar Kelimeler: Sürdürülebilir mimarlık, akıllı malzemeler, yenilenme gereksinimi, mimari uygulama bilinci.

\section{Smart Material in Architecture}

\begin{abstract}
The field of smart materials has experienced a great development in the 20th century, and with the beginning of the 21st century, it has further increased the speed of development. This leaded up to the architecture to develop itself, reshaped the way of thinking designers and construction professionals. It is becoming clear that the use of smart materials has become more and more developed and integrated in architectural applications needs to be considered not only as an application but also in the early stages of the design process. The research aims to explore the architectural characteristics and advantages of smart material systems, to explore the way to create architecture with better adaptable features, and ultimately to achieve the "state of adaptability" by providing the most suitable environment for users who are concerned with structural, climatic and architectural performances. As researchers in the area of architecture, by understanding the smart material systems technologies better, architecture can be improved and can reach the era of innovation.
\end{abstract}

Keywords: Sustainable architecture, smart materials, need for renewal, architectural application awareness.

Atıf/Citation: Topal, A.S. ve Arpacıoğlu, Ü. (2020). Mimarlıkta Akıllı Malzeme. Mimarlık Bilimleri ve Uygulamaları Dergisi, 5(2), 241-254.

DOI: $\underline{10.30785 / \mathrm{mbud} .784518}$ 


\section{Giriş}

Akıllı uçaklar, akıllı evler, şekil bellek dokuma kumaşlar, mikro makinalar, kendiliğinden oluşan yapılar, renk değiştiren boyalar, nanosistemler. Malzeme dünyasının kelime dağarcığı ilk 'akıllı malzeme' her şeyden önce kar kayaklarında ticari olarak ortaya çıktığında, 1992'den beri önemli ölçüde değişmiştir. 'Çevrelerine akıllıca yanıt veren yüksek mühendislik ürünü malzemeler' olarak tanımlanan akıllı malzemeler, 21. yüzyılın teknolojik ihtiyaçları için "kurtarıcı" yanıt haline gelmiştir.

Mimarlık ve malzemeler arasındaki ilişki Sanayi Devrimi'ne kadar oldukça açıktı. Malzemeler hem pragmatik olarak -faydaları ve kullanılabilirlikleri için- hem de usulen görünüşleri ve dekoratif nitelikleri için seçilmiştir. Bunların yanında malzeme seçiminde eldeki malzeme olanaklarını değerlendiren belirleyici bir kriter daha vardı. Yani belli bir konsept ve fonksiyona göre yapılan tasarımlar, aynı zamanda belli malzemelere göre yapılmıştır. Bu kapsamda 19. yüzyıl öncesi tasarımda malzeme kullanımı, form ve fonksiyondaki sorunlarla beraber malzeme olanaklarına bağlı olarak değerlendirilmektedir(Diri ve Gülçelik, 2018). Dahası malzemeler standartlaştırılmamış ve bu yüzden inşaatçılar ve mimarlar malzeme özelliklerinin ve performanslarının dışsal bir anlayışına güvenmek zorunda kalmıştır. Özünde, 19. Yüzyıl öncesinde malzeme bilgisi deneyim ve gözlem yoluyla elde edilmiştir. Ustabaşıları, mevcut malzemelerle çalışmak için gerekli bilgi ve becerileri, çoğunlukla talihsiz deneme ve yanılma yoluyla edinmişlerdir.

Sanayi Devrimi ile malzemelerin rolü önemli ölçüde değişmiştir. Mimarlar, malzeme özellikleri ve performansın sezgisel ve deneysel bir anlayışına dayanmak yerine, endüstriyel malzemeler ile karşı karşıya kalmaya başlamıştır. Gerçekten de, modern mimarlığın tarihi neredeyse mimari malzeme tarihinin merceğinden görülebilmektedir.

Akıllı malzemeler alanında, akıllı olduğu düşünülen malzemeleri ima eden malzemeleri ve hatta sistemleri ifade etmek için çeşitli terimler kullanılmaktadır. Bunlara örnek olarak uyarlanabilir sistemler, duyarlı malzemeler, bilgisayımsal malzemeler, akıllı sistemler vb. verilebilir.

Malzeme teknolojisindeki son gelişmelerle birlikte, akıllı malzemelerin daha yeni bir tanımı onu şu şekilde tanımlamaktadır: " Yerleşik veya dahili sensör (ler), aktüatör (ler) ve kontrol mekanizmasına / mekanizmalarına sahip olan ve bu sayede bir uyarıyı algılayabilen, ona önceden belirlenmiş bir şekilde ve kapsamda, uygun kısa sürede yanıt veren ve uyaran kaldırılır kaldırılmaz orijinal durumuna geri dönen bir malzeme "(Abdullah ve Al-Alwan, 2019).

Akıllı malzemeler, genellikle malzeme geliştirmedeki yörüngenin daha seçici ve uzmanlaşmış performansa doğru mantıklı bir uzantısı olarak kabul edilmektedir. Yüzyıllar boyunca bir kimse, malzemenin sınırlamalarına uyacak şekilde tasarlanan ahşap veya taş gibi standart bir malzemenin özelliklerini kabul etmek ve onunla çalışmak zorundaydı oysa 20. Yüzyılda bir kimse, özel olarak tanımlanmış bir ihtiyacı karşılamak için yüksek performanslı bir malzemenin özelliklerini seçmeye ya da tasarlamaya başlayabilir olmuştur. Akıllı malzemeler daha fazla spesifikliğe izin vermektedir, malzeme kullanılırken özellikleri değiştirilebilmektedir ve bu nedenle geçici ihtiyaçlara cevap vermektedir. Örneğin, ışığa maruz kaldığında fotokromik malzemeler renklerini (spektral geçirgenliğin özelliği) değiştirmektedir: Gelen ışık ne kadar yoğun olursa, yüzey o kadar koyu olmaktadır. Bu tek bir durum için optimize edilmektense çoklu durumlara yanıt verme yeteneği, akıllı malzemeleri tasarım paletine çekici bir katkı haline getirmektedir çünkü binalar her zaman değişen koşullarla karşı karşıya kalmaktadır. Sonuç olarak, akıllı malzemelerin daha da geleneksel yapı malzemelerinin yerini almaya nasıl başlayacağına dair birçok öneri getirilmiştir (Addington ve Schodek, 2005).

\section{Materyal ve Yöntem}

Anahtar kelimeleri etrafında oluşmuş olan çeşitli yerli ve yabancı literatür tarama araştırmaları, çalışma kapsamında irdelenip yapılmıştır. Çalışma konusuyla ilgili yayımlanmış kitap, tez, makale, bildiri gibi yazılı kaynaklar ve ilgili internet siteleri araştırılarak yapılmakta olan literatür taraması, önceden konuyla ilgili edinilen bilgiler ile karşılaştırılarak ve gelişmekte olan konulara daha derinden bakılarak anlatılmak istenilen başığın anlaşılmasının daha sade ve net bir biçimde sağlanmasına gayret edilmiştir. 
Akıllı malzemeler ve sürdürülebilirlik kavramları, kavramsal yönlerden incelenerek mimaride sürdürülebilir akıllı malzeme ve bu malzemelerin mimariye uygulanma kavramı irdelenmiştir. Bu amaca yönelik, sürdürülebilir akıllı malzeme kavramsal çerçevesine bakıldığında ekonomik, sosyal, çevresel boyutları saptanmış, 2000 yılından sonra önemi daha da belirginleşen bu yeni akıllı malzemelerin bir uyum içinde işlev göstermesi ve çevreye sağladığı yararlar ile birlikte sürdürülebilir mimarinin, kentsel gelişmenin ana itici gücü olması, bize düşünme şeklimizi etkileyen yeni olasılıklar ve potansiyeller sunması çalışmanın ana değerleri üzerinde olup konular ve malzemelerin sınıflandırılması bu ilkeler etrafında şekillenmiştir. Çalışma sonucunda, akıllı malzemeler teknolojisi sürdürülebilirliği yeni seviyelere taşınmasının sorgulanması konusunda destekler olması beklenmektedir.

\section{Bulgular ve Tartışma}

\subsection{Akıllı malzemelerin özelikleri}

Akıllı malzemeler, onları diğer malzemelerden ayıran özel dinamik özelliklere sahip bir grup malzemedir. Özellik değiştirme, enerji değişimi ve tersinirlik gibi özelliklere sahip olmanın yanı sıra çevreyi algılayıp tepki verebilmektedir. Akıllı malzemelerin bu özellikleri moleküler düzeyde bile görülebilmektedir. Bununla birlikte, bazı örneklerde, akıllı malzemeler grubunda yer almayan malzemeler de bu özelliklerin bazılarını barındırabilmektedir. Mesela ahşabın neme göre davranışı veya artan sıcaklık yoluyla metallerin genleşmesi. Bir malzemenin akıllı olup olmadığını belirlemek için tüm akıllı malzemelere dâhil edilecek bazı belirli özellikler vardır. Addington ve Schodek $(2005$,$) akıllı$ malzemelerin özelliklerini şu şekilde belirtmektedir: Dolaysızlık, geçicilik, doğruluk, seçicilik ve kendi kendine çalıştırma. Malzeme tüm bu özelliklere sahipse, akıllı malzeme olarak adlandırılabilmektedir, aksi takdirde akıllı olarak adlandırılamamaktadır. Dolaysızlık, akıllı malzemelerin zamansal oldukları için gerçek zamanlı olarak yanıt vermeleri gerektiği anlamına gelmektedir. Durumlar arasında sık sık değişmekte veya enerjiyi derhal dönüşmektedirler. Geçicilik, değişen çevresel koşullara bağlı olarak değişebilecekleri anlamına gelmektedir. Doğruluk, farklı çevre durumlarının neden olduğu değişikliklerin tekrarlanabilir ve geri alınabilir olması gerektiği anlamına gelmektedir. Seçicilik, çevresel koşullara dikkatle karşılık verdikleri ve değişkenliklerini kontrol etmek için öngörülebilir oldukları anlamına gelmektedir. Kendiliğinden çalıştırma ise materyalin moleküler yapı, kompozisyon, kurgu veya kimyasal özelliklerinin dahili programlaması yoluyla kendini harekete geçirmesi anlamına gelmektedir(Ürkmez, 2019).

Malzeme niteliklerinin değişmesi genellikle dış bir uyarıyla beraber oluşan bozulmalar olan göçme, korozyon, çürüme vb. gibi sorunlarla bağdaştırılan bir durum olduğundan malzeme bilimindeki alışıımış anlayış, malzemelerin kullanım süresince mümkün olduğunca niteliklerini korumasıdır. Alışımış(klasik) malzeme anlayışında malzemeden kullanım boyunca değişime uğramaması dışında bir beklenti beklenmemektedir. Buna karşılık akıllı malzemelerin kullanımında malzemelerin kullanıldıkları sürece dış uyarıcılara karşı işlevlerine yardımcı olacak faydalı nitelik değişimleri yaparak sürdürülebilirliklerini sağlamaları beklenmektedir. Okay (2003)'a göre “bir şekilde bütün malzemelerin belli bir derece akılıılı̆ı mevzubahistir. Örnek vermek gerekirse metaller ısıtıldıkları zaman genleşmektedir, aynı zamanda ısıtıldıklarında daha kolay işlenmektedir, bazı metallerin (yarı iletkenler) ısıtılması ile iletkenlikleri artmaktadır. "Ancak malzemeyi gerçekten akıllı yapan bu tip değişimlerin malzemenin dizaynı ile ortaya çıkmasıdır" (Okay, 2003, s.5). Bu nedenle akıllı malzemeler bizatihi tasarlanmış/önceden planlanmış malzemelerdir.

\subsection{Akıllı malzemelerin sınıflandırılması}

Addington ve Schodek (2005), akıllı malzemeleri iki gruba ayırmaktadır. Birinci gruptaki malzemeler, çevredeki ortamdaki dış uyaranlardaki bir değişime doğrudan tepki olarak (kimyasal, elektrik, manyetik, mekanik veya termal) özelliklerinden bir veya daha fazlasında değişikliklere uğramaktadır. Örneğin, bir fotokromik malzeme, yüzeyindeki ultraviyole radyasyon miktarındaki bir değişime tepki olarak rengini değiştirmektedir. Bu tür davranışa sahip olan malzemelere nitelik değişimi yapan akıllı malzemeler diyebiliriz. Öte yandan, ikinci tip akıllı malzeme enerjiyi bir formdan diğerine dönüştürmektedir. Bu sınıf; fotoelektrik, termoelektrik, piezoelektrik, fotolüminisan ve elektrostriktif davranış türlerine sahip materyalleri içermektedir (Addington ve Schodek, 2005, s. 15-45). 
İki grup arasında bir fark vardır. "Nitelik değişimi yapan" akıllı malzemelerin aksine, "Enerji dönüşümü yapan" akıllı malzemeler "belirli bir işlev türü sağlayacak şekilde oluşturulmuş birkaç tane daha temel malzemeden oluşmaktadır"(Addington ve Schodek, 2005, s. 17).

Örneğin, bir fotovoltaik hücre farklı malzemelerin farklı katmanlarından oluşmakta ve yeterli bir çalışma voltajı elde etmek için hücrelerin modüller oluşturacak şekilde seri bağlanması gerekmektedir(Messenger ve Ventre, 2013; Şensan, 2019).

Akıllı materyallere odaklanan kitapları ile akıllı materyallerin sınıflandııımasında iki ana otoriterden bir diğer kişi olan Ritter (2007) de akıllı malzemeleri farklı kategorilerde sınıflandırmıştır (Ürkmez, s. 14). Ritter, akıllı materyalleri özelliklerine göre üç kategoride analiz etmiştir: Özellik değiştiren, enerji dönüştüren ve madde dönüştüren akıllı malzemeler(Şensan, 2019, s. 38).

Ritter, şekil değiştiren, renk ve optik özelliğini değiştiren, adezyon değiştiren, ışık yayan, elektrik üreten, enerji depolayan gibi özellikler gösteren çeşitli akıllı malzemeleri, özellik değiştiren ve enerji dönüşümü yapan akıllı malzemelerin alt grubuna yerleştirmiştir. Özellik değiştirme sınıfında yer alan şekil değiştiren malzemeler, özgün şekil ve/veya boyuttan gözlemlenebilir bir değişikliğe neden olan harici bir kaynaktan sonra orijinal şeklini ve/veya boyutunu koruyabilen malzemelerdir. Bu durumda dış uyaranlar ışık, basınç, sıcaklık, manyetik alan ve hatta kimyasal uyaranlar arasından olabilmektedir (Ritter, 2007; Ürkmez, 2019, s. 18).

\subsection{Nitelik değişimi yapan akıllı malzemeler}

Bu gruptaki akıllı malzemeleri incelediğimizde, akıllı malzemelerin bir veya birkaç niteliğini (renk, şekil, sertlik, iletkenlik, akışkanlık, hal, faz vb.) tersinir -eski haline geri dönebilecek- biçimde dış uyaranların (ışık, sıcaklık, basınç, elektrik alan, manyetik alan, kimyasal ortam vb.) etkisiyle değiştirme özelliği olduğunu görmekteyiz. Değişiklikler doğrudan ve tersinirdir(geri dönüşümlüdür). Bu değişikliklerin meydana gelmesi için harici bir kontrol sistemine gerek yoktur. Sürdürülebilirlik açısından faydalı nitelik değişimleri yaparak bu malzemelerin dış çevreye göre sürekli tepki vermesiyle beraber kullanılması çevreye ve canlılara birçok yarar sağlamaktadır. Bu yarar yapının enerji tüketimini azaltmak, yapı fiziği niteliklerini iyileştirmek, kolay kontrol imkânına ulaşmak, yaşam ömrünü uzatmak, bakım giderlerini düşürmek, canlıların konfor şartlarını iyileştirmek gibi vb. birçok yollarla sağlanabilmektedir.

Çizelge 1. Nitelik değişimi yapan akıllı malzemelerle yapı uygulamaları

\begin{tabular}{|c|c|c|}
\hline Akıllı Malzeme Sınıfı & Dış uyaran & Yapıda kullanım yöntemi \\
\hline Foto-kromik malzeme & Işık & Foto-kromik camlarla pasif kontrollü akıllı cephe \\
\hline Termo-kromik malzeme & Sıcaklık & Termo-kromik camlarla pasif kontrollü akıllı cephe \\
\hline Elektro-kromik malzeme & Elektrik & Elektro-kromik camlarla aktif kontrollü akıllı cephe \\
\hline \multirow[t]{2}{*}{ Fotokatalik Malzeme } & Işık & $\begin{array}{l}\text { 1. Fotokatalitik dış yapı elemanları (beton, membran, cephe } \\
\text { panelleri vb.) }\end{array}$ \\
\hline & & 2. Fotokatalitik yapı bileşenleri (seramik, cam vb.) \\
\hline \multirow[t]{2}{*}{ Faz Değiştiren Malzeme } & Sıcaklık farkı & 1. Isı yalıtımı sağlayan harç, dolgu katkıları \\
\hline & & 2. Isı depolayan akıllı cepheler \\
\hline
\end{tabular}

Kromatik malzemeli camlar bu tür akıllı malzemelerin kullanımında en yaygın olanları olmaktadır. Akıllı camlar optik ve termal özelliklerini ışık (fotokromik), ısı (termokromik) veya elektrik potansiyeli (elektrokromik) etkisi altında değiştirmektedir. Bu camlar, bina cephelerine oldukça duyarlı dinamik iklim kontrolü potansiyeli sunmaktadır. Bu akıllı malzemeler, lamine cam sistemlerine dâhil etmek için plastik laminatlar halinde de mevcuttur (Lyons, 2010, s. 254).

\subsubsection{Fotokromik malzeme}

Fotokromik malzemeler, fotokromikler ve UV'ye duyarlı malzemeler, ışığa tepki olarak renklerini geri dönüşümlü olarak değiştirebilen malzemeler veya bileşenlerdir (Ritter, 2007, s. 73). Fotokromik 
camlar, ultraviyole veya kısa dalga görünür ışığa duyarlı gümüş halojenür kristalleri içermektedir. Rengin koyuluğu doğrudan gelen ışı̆̆ın yoğunluğu ile ilgilidir ve tamamen geri dönüşümlüdür. Binalarda kullanım için bu malzemeler, iç ışınımdan ziyade güneş ışınımındaki değişikliklere otomatik olarak tepki vermeleri dezavantajına sahiptir (Lyons, 2010).
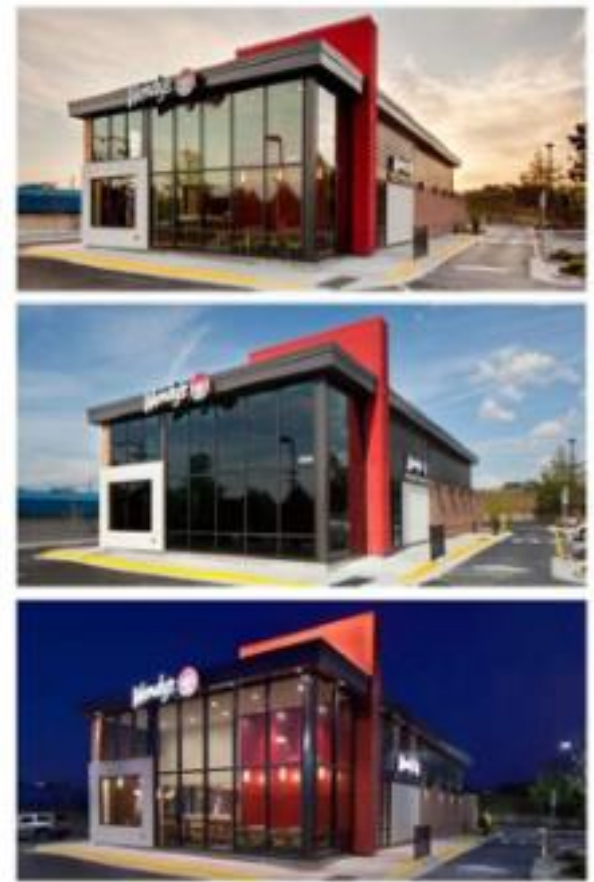

Morning

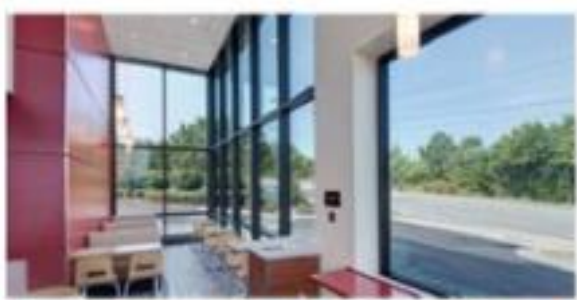

Midday

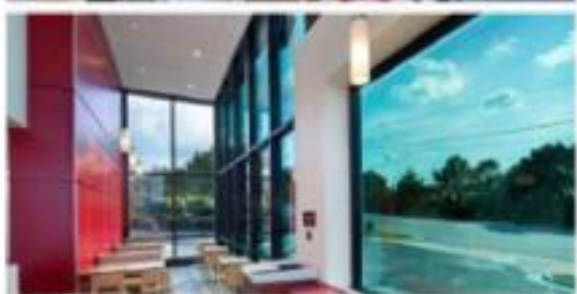

Night

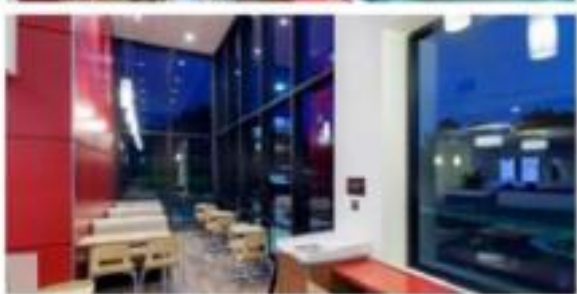

Şekil 1. Fotokromik cam malzemesinin dış çevre ile rengini değiştirmesi (Alibaba, 2019).).

\subsubsection{Termokromik malzeme}

Termokromik malzemeler, sıcaklığa tepki olarak optik özelliklerini (ör. Şeffaflık) geri dönüşümlü olarak değiştirebilen malzemeler veya bileşenlerdir (Ritter, 2007, s. 80). Termokromik malzemeye bir termal enerji (ısı) girişi moleküler yapısını değiştirmektedir. Yeni moleküler yapı, orijinal yapıdan farklı bir spektral yansıtma özelliğine sahip olmakta; sonuç olarak, malzemenin "rengi" -elektromanyetik spektrumun görünür aralığındaki yansıyan ışınımı- değişmektedir (Addington ve Schodek, 2005, s. 15).

Birçok akıllı malzemenin doğal olarak sensörler olarak işlev görebileceğini görebilmekteyiz. Sensörler olarak görevlerinde akıllı bir malzeme, algılanabilir bir tepki oluşturarak ortamındaki bir değişime yanıt vermektedir. Böylece, bir termokromik malzeme, renk tepkisi yeteneği vasıtasıyla bir ortamın sıcaklığındaki bir değişikliği algılamak için doğrudan bir cihaz olarak kullanılabilmektedir.

Termokromik malzemelerin çeşitli avantajları araştırılıp öğrenildikten sonra da bazı sanatçılar bu malzemelerin bir yapıda nasıl uygulanacağını göstermek için çalışmalar yapmışlardır. Örneğin Şekil 2' de görülen dışbükey kavisli bir duvar, sıvı kristallerden ve sentetik bir bağlayıcıdan oluşan geniş bir sıcaklığa duyarı renk değiştiren boya ile kaplanarak akıllı malzeme kullanımının tasarım paletinde de ne denli etkili olabileceği gösterilmiştir. 

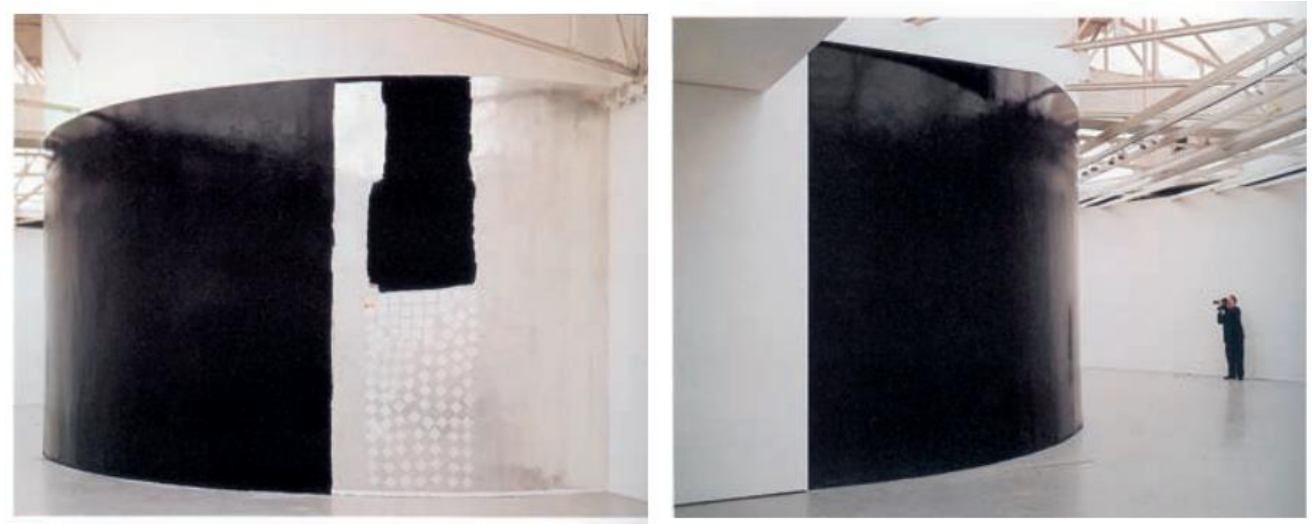

Şekil 2. Venedik'teki bianelde Alman sanatçı Sigmar Polke, sıvı kristallerden ve sentetik bir bağlayıcıdan oluşan geniş bir sıcaklık duyarlı, renk değiştiren boya alanı ile dışbükey kavisli bir duvar kaplamıştır (Ritter, 2007).

\subsubsection{Elektrokromik malzeme}

Kromofor olarak da bilinen elektrokromik malzemeler, bir voltaj uygulandığında uygulanan yüzeyin optik rengi veya opaklığı etkilenen malzemelerdir(Monk, Mortimer, \& Rosseinky, 2007). Metal oksitler arasında, tungsten oksit (WO3) en çok incelenen ve iyi bilinen elektrokromik malzemedir. Diğerleri molibden, titanyum ve niyobyum oksitleri içerir, ancak bunlar optik olarak daha az etkilidir.

Birkaç elektrokromik cihaz geliştirilmiştir. Elektrokromizm, elektrokromik pencerelerin veya "akıllı cam" ın üretiminde yaygın olarak kullanılmaktadır ve daha yakın zamanlarda sahteciliğe karşı sistemler olarak kağıt substrat üzerinde ambalaja entegre elektrokromik görüntüler kullanılmaktadır. $\mathrm{NiO}$ malzemeleri, tamamlayıcı elektrokromik cihazlar için, özellikle akıllı pencereler için karşıt elektrotlar olarak geniş çapta incelenmiştir.

ICE 3 hızlı trenlerinde yolcu kabini ile sürücü kabini arasında elektrokromik cam paneller kullanılmaktadır. Standart mod, net bir görüntü sağlamaktadır ve esas olarak yolcuların görüntüsünden göze hoş görünmeyen zamanları gizlemek için sürücü tarafından buzlu (yarı saydam) olarak değiştirilebilmektedir. Elektrokromik pencereler Boeing 787 Dreamliner'da kullanılmaktadır (Şekil 3), (Suze, 2016).

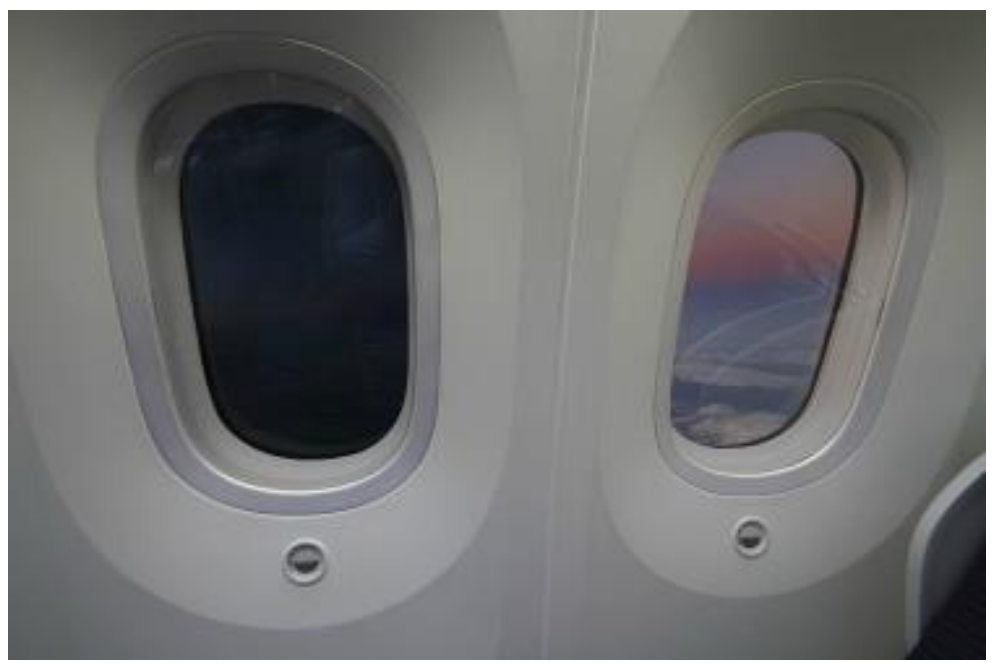

Şekil 3. Elektrokromik camlar, kullanıcıların esnek ihtiyaçlarını karşılamak amacıyla uçak camlarında da kullanılmaya başlanmıştır (Elektrik elektronik egitimi, 2017). 
Elektrokromik malzemelerin çalışma prensibi, üzerinde belirli bir voltaj uygulayarak malzemeye elektrik yüklenmesiyle ya da bu elektrik yükünü kaybetmesiyle beraber gerçekleşmektedir. Malzemeye uygulanan voltajın pozitif olması durumunda malzeme rengini kaybederek saydamlaşmaya başlamakta, malzemeye uygulanan voltajın negatif olmasıyla da malzeme rengini geri kazanmaktadır. Elektrokromik oksit sınıfında yer alan tungsten oksit malzemesi çok katmanlı bir biçimde 1 mikron kalınlığında olarak cam üzerine kaplanarak üzerine $1 \mathrm{~V}$ ile $5 \mathrm{~V}$ arasında gerilim uygulandığı zaman cam yüzeyi ışık geçirgenliğini kaybederek renkli olmaya başlamaktadır. Cama uygulanan gerilim azaltılmaya başlandığı zaman ise malzeme tekrar eski berrak haline gelerek ışık geçirgenliği artmaktadır. Bu minvalde 'ayarlanabilir-kullanıcı ayarlı camlar' çeşitli amaçlar, uygulamalar için üretilebilmektedir (Anonim, 2017).

\subsubsection{Fotokatalitik malzeme}

Kentsel merkezler; yüksek yoğunluklu sanayileşme, içten yanmalı araç trafiği ve civarlardaki elektrik üretimi nedeniyle genellikle düşük hava kalitesine sahiptir. Bu kötü hava kalitesi, fotokimyasal duman, zayıf görünürlük ve bir sürü zararlı sağlık etkisi gibi olumsuz sonuçlar doğurabilmektedir. Fotokimyasal duman; güneş ışığından gelen fotonlar ile azot dioksit, uçucu organik bileşikler (VOC), oksijen ve ozon gerektiren bir dizi kimyasal reaksiyon sonucu oluşmaktadır. Dumanın etkileri, ormanlara ve tarımsal ürünlere verilen zararın yanı sıra göz ve solunum yollarında tahriş, görüşün azalması, ozon birikimi ve maruziyeti olarak sayılabilmektedir. Fotokimyasal dumanın başlatıcılarına engel olmak, binaların çevreyi iyileştirmede aktif bir rol oynayabilmelerinin bir yolunu sunmaktadır.

Bu hedefe ulaşmaya yardımcı olabilecek yenilikçi bir teknoloji fotokatalitik çimentodur - azot ve kükürt oksitler, karbon monoksit ve uçucu organik bileşikler (VOC) gibi yaygın hava kirleticileri ile reaksiyona girmek ve nötralize etmek için gün ışığını kullanmaktadır; reaksiyon betonun yüzeyinde gerçekleşmektedir ve ortaya çıkan inert nitratlar elle veya yağmurla yıkanabilmektedir. Parlak ve berrak bir günde, fotokatalitik işlem azot oksitleri, aldehitleri, benzenleri ve klorlu aromatik bileşikleri \%90'a kadar ortadan kaldırabilmektedir. Binada fotokatalitik çimentoların kullanımı ile ilgili araştırmalar on yılı aşkın bir süredir ilerlemektedir ve bu gelişen teknoloji en çok kaldırım ürünlerinde bulunmaktadır(Nikolov ve Fox, 2014).

Fotokatalitik malzemelerin yararlı etkisi betondan ayrı olarak seramik yüzey kaplamalarında, cam ürünlerinde, duvar kağıtlarında, dış cephe boyalarında, yapı membran ürünlerinde de ince filmlere kaplama veya pigment olarak katma yoluyla kazandırılabilinir.

\subsubsection{Faz değiştiren malzeme}

Yapı malzemelerinde kullanılan faz değiştiren malzemeler (PCM) oda enerji tasarrufunu, ısı yalıtım performansını ve insan konforunu artıran malzemeler olarak sayılmaktadır. Tavanlarda, duvar panellerinde, ISI yalıtım levhalarında, ısıtma zeminlerinde ve diğer endüstrilerde yaygın olarak kullanılmaktadırlar. Ayrıca stadyumlarda yıl boyunca stadyumların her daim yeşil kalmasını sağlamak için kullanılabilmektedir.

PCM malzemeli cephe sistemleri (ticari adı: GlassX) gibi uygulamalar veya harç ve dolgu malzemesine katılan polimer olarak mikrokapsüllenmiş parafin mumu esaslı PCM katkısı (ticari adı: Micronal) faz değiştiren malzemelerin ısı depolama özelliklerini kullanarak yapının daha az enerji tüketmesini sağlamaktadır( Cloudhem, 2020). 


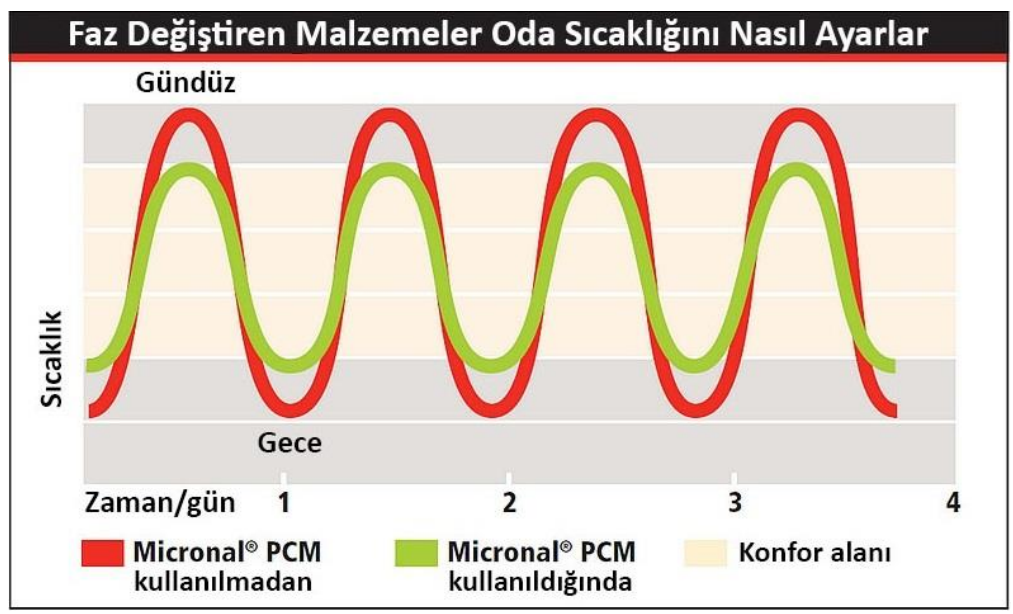

Şekil 4. Faz değiştiren malzemelerin yapı malzemelerine uygulanması ile daha hafif sıcaklık değişimleri olmakta bu da daha fazla enerji etkin iklim kontrolü anlamına gelmektedir (PCM, 2020) [Yazar tarafından düzenlenmiştir].

Grafikte, ticari adı Micronal olarak piyasaya sürülen faz değiştiren bir malzemenin çalışmasında odanın sıcaklığında daha yumuşak değişimler yaratarak kullanımının rahatça sürdürülebildiği görülmektedir.

- Yaz aylarında gün içinde sağlanan güneş enerjisi, bina içinde aşırı sıcaklık dalgalanmaları olmaksızın, duvarlarda depolanmaktadır. Bir evde $3{ }^{\circ} \mathrm{C}$ ila $5{ }^{\circ} \mathrm{C}$ arasında oda sıcaklığını yumuşatmak mümkündür.

- Kışın aynı şekilde, güneşin ürettiği ıSı, duvarlara dâhil PCM'de depolanabilmektedir; bu, gün boyunca biriken ısıyı günün sonunda ve gece boyunca geri verebilmesini sağlayacaktır.

Sadece $1.5 \mathrm{~cm}$ kalınlığında bir Micronal PCM alçı duvar levhası, $9 \mathrm{~cm}$ beton veya $12 \mathrm{~cm}$ tuğla ile aynı termal depolama kapasitesine sahiptir. Bu nedenle faz değiştiren malzemeler, hem yapı yenileme çalışmalarında hem de modern hafif yapı sistemleri için ideal yapı malzemesi olarak kabul edilebilmektedir (PCM, 2020).

\subsection{Enerji dönüşümü yapan akıllı malzemeler}

İkinci bir genel akıllı malzeme sınıfı, enerjiyi bir formdan başka bir formdaki enerjiye dönüştürenlerden oluşmaktadır.

Bu sınıftaki akıllı malzemeler ışık, kuvvet, ısı gibi dış bir uyarandan aldıkları enerjiyi diğer bir enerji türüne tekrar tekrar, doğrudan ve tersinir bir biçimde çevirmektedirler. Örneğin fotoelektrik malzemeler üzerine gelen ışı enerjisini elektrik enerjisine çevirmektedir. Normalde faydalanılmayacak bir enerji formunu binanın en ihtiyaç duyduğu enerjiye çevrilmesini sağlaması bu malzemelerin binalarda kullanımını önemli hale getirmektedir.

Bununla birlikte, 'enerji dönüşümü yapan malzemeler' olarak tanımlandığında, burada 'malzeme' teriminin kullanımının biraz yanıltıcı olabileceğinin farkında olmalıyız. Bu sınıftaki "malzemelerin" çoğu, belirli bir işlev türü sağlayacak şekilde oluşturulan birkaç temel malzemeden oluşmaktadır. Örneğin bir termoelektrik malzeme, aslında farklı malzemelerin çoklu katmanlarından oluşmaktadır. Ortaya çıkan montaj belki de basit bir cihaz olarak daha iyi tanımlanabilir. Bununla birlikte, 'malzeme' terimi, büyük ölçüde kavramsal olarak düşünülme ve kullanılma biçimleri nedeniyle bu cihazlarla ilişkilendirilmeye devam etmektedir. Uygulamaya yönelik düşünme, burada 'malzeme' teriminin kullanılmasını sağlamaktadır (Addington ve Schodek, 2005, s. 17-18). 
Çizelge 2. Enerji dönüşümü yapan akıllı malzemelerle yapı uygulamaları

\begin{tabular}{lll}
\hline Akıllı Malzeme Sınıfı & Dış uyaran & Yapıda kullanım yöntemi \\
\hline Fotoelektrik malzeme & Işık & Fotovoltaik paneller \\
Piezoelektrik malzeme & Kuvvet & $\begin{array}{l}\text { 1. Kendi enerjisini üreten malzeme sistemi } \\
\text { 2. Elektrik üreten döşeme kaplamaları }\end{array}$ \\
& & $\begin{array}{l}\text { 3. Elektrik üreten rüzgar tüyleri (Teori) } \\
\text { Piroelektrik malzeme }\end{array}$ \\
Isı & $\begin{array}{l}\text { Gün boyunca dış yapı bileşenlerinin ısınıp soğumasıyla } \\
\text { elektrik üretimi (Teori) }\end{array}$ \\
Elektrolüminesans Malzeme & Elektrik & Elektrik üreten yapı kabukları (Teori ) \\
\hline
\end{tabular}

$\mathrm{Bu}$ tür enerji dönüşümü yapan malzemelerin en yaygın olarak kullanım ve uygulanmasında fotoelektrik akıllı malzemeler olduğu görülmektedir. Fotoelektrik malzemeler olarak üzerine düşen elektronun görevinin özellikle elektrik voltajı üretmek olduğunu vurgulamak için bu malzemeler 'fotovoltaik malzemeler' olarak isimlendirilmektedir.

Bir fotovoltaik sistem, her biri elektrik enerjisi üreten bir dizi güneş hücresi içeren güneş modülleri kullanmaktadır. Fotovoltaik sistem tesisatları yere, çatıya, duvara monte edilebilmekte veya su üzerinde yüzdürülebilmektedir. Montaj sabitlenebilmekte veya gökyüzündeki güneşi takip etmek için bir güneş takip cihazı kullanılabilmektedir.

Solar fotovoltaik sistemlerin bir enerji kaynağı olarak belirli avantajları vardır: Bir kez kurulduğunda, çalışması kirlilik ve sera gazı emisyonu oluşturmamaktadır, güç ihtiyaçları açısından basit ölçeklenebilirlik göstermektedir.

Fotovoltaik sistemler 1990 'lardan bu yana özel uygulamalarda bağımsız kurulumlar ve şebekeye bağı fotovoltaik sistemler olarak kullanılmaktadır (Bazilian vd., 2013). Fotovoltaik modüller ilk kez Alman çevreciler ve Eurosolar örgütünün on bin çatı programı için devlet fonu aldığı 2000 yılında seri üretilmiştir (Palz, 2013).

Teknolojideki ilerlemeler ve artan üretim ölçeği her durumda maliyeti düşürmüştür(Shubbak, 2019), güvenilirliği ve fotovoltaik tesislerin verimliliğini artırmıştır(Swanson, 2009). Güneş enerjisiyle üretilen elektrik için ayrıcalıklı tarife garantileri gibi net ölçüm ve finansal teşvikler birçok ülkede güneş fotovoltaik kurulumlarını desteklemiştir (Sawin, Martinot, Sonntag-O'Brien, McCrone, vd., 2011). 100 'den fazla ülke artık güneş fotovoltaik sistemlerini kullanmaktadır (Anonim, 2020).

Fotoelektrik akıllı malzeme kökenli yapı bileşenleri olan fotovoltaik panel sistemleri çok farklı sistem çeşitliliklerinde, farklı ölçeklerde kullanılma avantajına sahiptir. Bunlardan biri yapraklar biçiminde düzenlenmiş yeni kuşak fotovoltaik yapı bileşenlerinde bir örnek olan 'Solar Ivy' sistemleridir.

Küçük, esnek güneş hücreleri, paslanmaz çelik ağ sistemine bağı yapraklara benzemektedir. Yaprakların "önünde" fotovoltaikler güneş ışı̆̆ını yakalamakta ve elektrik üretmektedir; arka tarafta yaprak hareketinin rüzgardan kaynaklandığı durumlarda güç üreten piezoelektrik jeneratörler bulunmaktadır. 28 metrekarelik Solar Ivy alanı 85 Watt güneş enerjisi üretebilmektedir. Sistemin avantajlarından biri, hafif olması nedeniyle dikey bir duvara kolayca monte edilebilmesidir. 


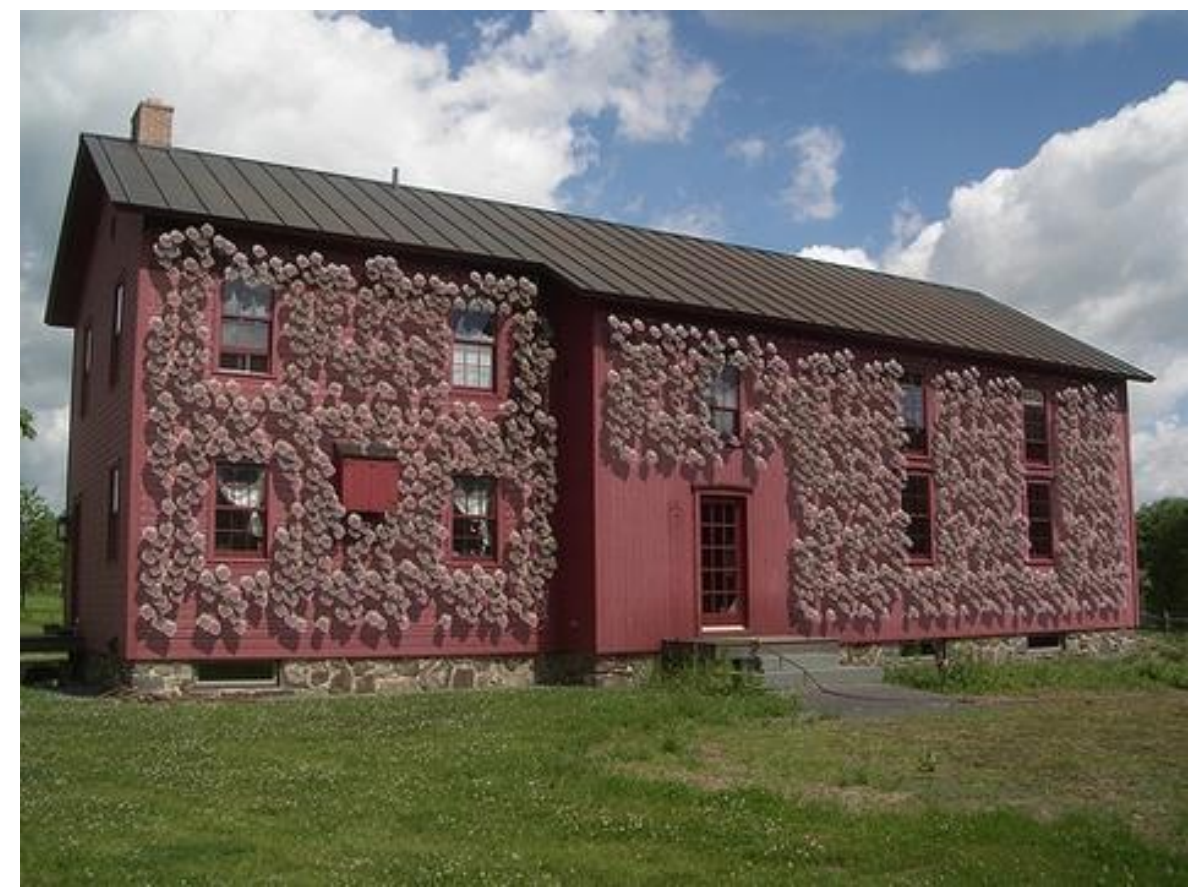

Şekil 5. 'Solar Ivy' fotovoltaik sistemi ile kaplanmış bir bina cephesi (Solaripedia, 2020a).

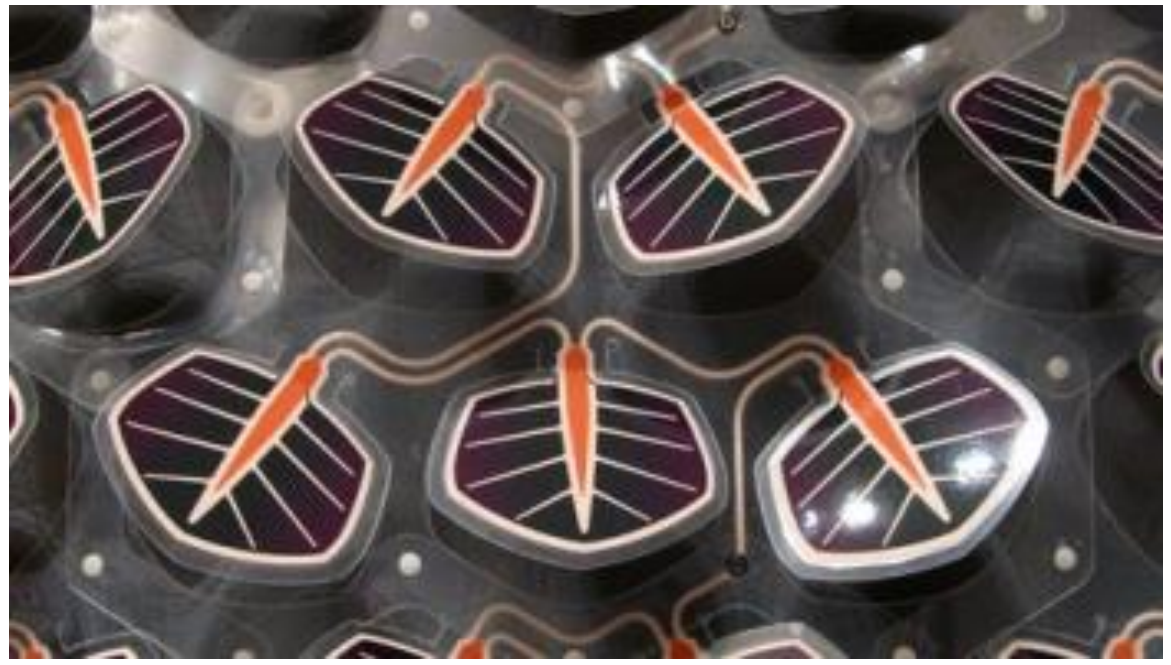

Şekil 6. 'Solar Ivy' sistemi modülleri yakından görünüş (Solaripedia, 2020b).

Güneş dışında yenilebilir enerji kaynaklarından enerji üretmek için yapılan araştırmalar, akıllı malzemeli yapı bileşenleri ve yapı elemanları içinde sürmektedir. Enerji dönüşümü yapan akıllı malzemelere bir diğer örnek olarak bir dış etken tarafından üzerine uygulanan kuvvet sonucunda elektrik potansiyeli oluşturan piezoelektrik malzemeler verilebilir. Örneğin piezoelektrik akıllı malzeme ile oluşturulmak istenen sürdürülebilir bir biçimde çalışması düşünülen Şekil 7'de görüldügü gibi MATscape projesinde Mitchell Joachim (2005) tarafından yapı kabuğuna önerilmiş olan küçük rüzgâr tüyleri şeklinde malzemeler yardımıyla rüzgâr enerjisinden elektrik enerji elde etmek amaçlanmıştır. Bu rüzgâr tüyleri, üzerine gelen rüzgâr yüküyle beraber titreşmektedirler. Mekanizma üzerinde rüzgârın neden olduğu titreşimlerle canlanmaya başlayan küçük rüzgâr tüyleriyle oluşan mekanik enerji, tüylerin hemen altındaki sistem ile beraber elektrik enerjisine çevrilmektedir. Elektrik enerjisine çevrilen bu enerji daha sonra depolanmak için yararlı olabilecek uygulamalar için yapının içinde işlev alabilmekte veya elektrikli araçlar gibi yapı dışındaki herhangi başka bir araca yakıt sağlanması avantajını da gösterebilmektedir (aktaran Orhon, 2013). 


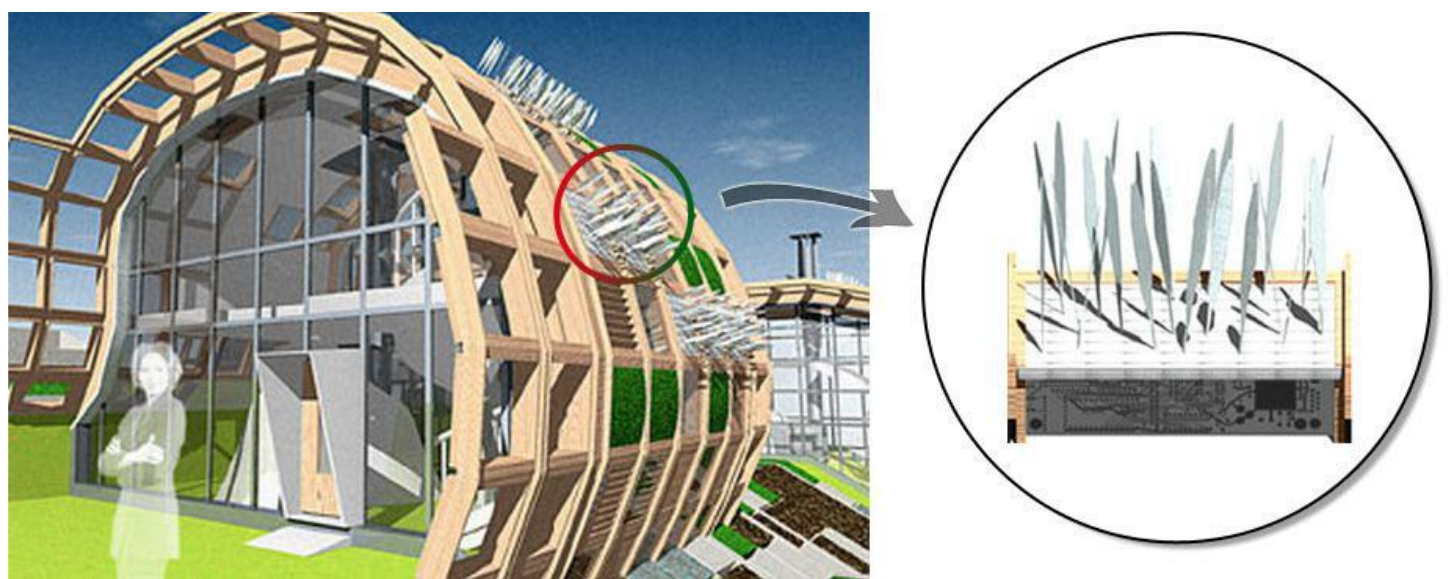

Şekil 7. MattScape Projesinde rüzgar tüyleri şeklinde malzemelerden elektrik üretmeyi sağlamak için yapı kabuğunda nasıl kullanılacağına dair Mitchell Joachim tarafından yapılan tasarım (Orhon, 2013).

Piezoelektrik etki, inversiyon simetrisi olmayan kristalli malzemelerde mekanik ve elektriksel durumlar arasındaki lineer elektromekanik etkileşimden kaynaklanmaktadır(Gautschi, 2002). Piezoelektrik etki(uygulanan bir mekanik kuvvetten kaynaklanan iç elektrik yükü üretimi) geri dönüşümlü(tersinir) bir işlemdir: Piezoelektrik etki sergileyen malzemeler ters piezoelektrik etki de göstermektedir; bu etki uygulanan elektriksel alandan kaynaklanan mekanik bir gerilimin iç üretimi olarak belirtilebilmektedir. Örneğin, kurşun zirkonat titanat kristalleri, statik yapıları orijinal boyutun yaklaşık \%0.1'i kadar deforme olduğunda ölçülebilir piezoelektriklik üretecektir. Diğer taraftan, aynı kristal malzemelere harici bir elektrik alanı uygulandığında statik boyutlarının yaklaşık \%0.1'ini değiştirecektir. Kurşun zirkonat titanat (PZT) içeren boyalar, metal konstrüksiyonda (çelik, alüminyum) üzerinde uygulandığı yapının yapısal davranışını izlemek için boyanın elektrik potansiyelini izleyen sensörlerle entegre bir biçimde kullanılmaktadır. Bu tür akıllı boya Gateshead Millennium Bridge'de kullanılmıştır (Newcastle, İngiltere, 2001, Wilkinson Eyre Architects)(Orhon, 2012). Ters piezoelektrik etki ultrasonik ses dalgalarının üretiminde de kullanılmaktadır (Krautkrämer ve Krautkrämer, 1990).

Yapılarda enerji üretim potansiyeline sahip olan bir başka akıllı yapı malzemelerine örnek olarak piroelektrik ve termoelektrik malzemeler de verilebilir. Piroelektrik malzemelerden enerji elde etmek için malzemeye dışarıdan ısı verilmektedir. Piroelektrik malzemenin kullanım yöntemine örnek olarak gün içinde ısınıp soğuyan dış yapı bileşenlerini vermek mümkündür. Bu malzemelerin mimarlık, çevre ve sürdürülebilirlik uygulamaları açısından uygun bir biçimde kullanılması için çeşitli araştırmalar günümüzde hala sürmektedir. Günlük sıcaklık farklarının yüksek olduğu iklimlerde, piroelektrik malzeme kullanım verimliliğinin diğer iklimlere göre daha fazla olması beklenmektedir. Türkiye' de günlük sıcaklık farkı aralığının açılmasında önemli bir etken olan nem miktarı oranının en düşük olduğu iklim çeşidi karasal iklimdir. Dolayısıyla Türkiye' de piroelektrik malzemelerin çalışma koşullarına en uygun olan iklim, gün içi sıcaklık farkının yüksek olmasından dolayı Konya, Erzincan yerleşimleri arasında kalan karasal iklim bölgesi olduğu görülmektedir. Günlük sıcaklık farkının yüksek olduğu yerlere dünya ölçeğinde de bakıldığında nem miktarının dünyanın diğer alanlarına göre daha düşük olduğu çöl bölgeleri görülmektedir.

\section{Sonuç}

1 - Mimarlık alanında uygulanması düşünülen akıllı malzemeler öncelikle bir doku veya yüzey olarak görünmemekte, ancak tüm mimari derinliğinde ortaya çıkmakta ve deneyimlenmektedir. Sonuç olarak mimarlar, malzemeyi tasarım işleminin her aşamasında çevreye uyarlanabilir ve verimli olabilecek davranışa sahip fonksiyonel bir unsur olarak görmelidir.

2 - Yirmi birinci yüzyıl, artan enerji maliyetleriyle beraber çevreye yönelik tehditlerin bastırılması, sürdürülebilir mimari tasarımın uzun vadeli kaynakların korunmasında ve genel yaşam kalitesinde çarpıcı kazanımlar sağlayabileceği konusunda sıkı bir çözüm sağlama sürecini başlatmıştır. Tüm bunları desteklemek, yalnızca sürdürülebilir fikirleri geliştirmekle kalmayıp aynı zamanda karlı bir 
şekilde üretilen temiz teknoloji ürünleri ve süreçlerinin portföyüdür. Akıllı Malzemeler teknolojisi sürdürülebilirliği yeni seviyelere taşımaya hazırdır.

3 - Mimari ve inşaat malzemeleri, yapıları ve sistemleri arasında ilişki, bileşim, interaktif ve karmaşık bir bağlantı vardır. Bu ilişki, mimari yenilikçi tasarımın ana itici gücü haline gelmiştir, mimari alanda ortaya çıkmaya başlayan yeni akıllı malzemeler, bu tasarım yaklaşımını vurgulamakta ve bize düşünme şeklimizi etkileyen yeni olasılıklar ve potansiyeller sunmaktadır.

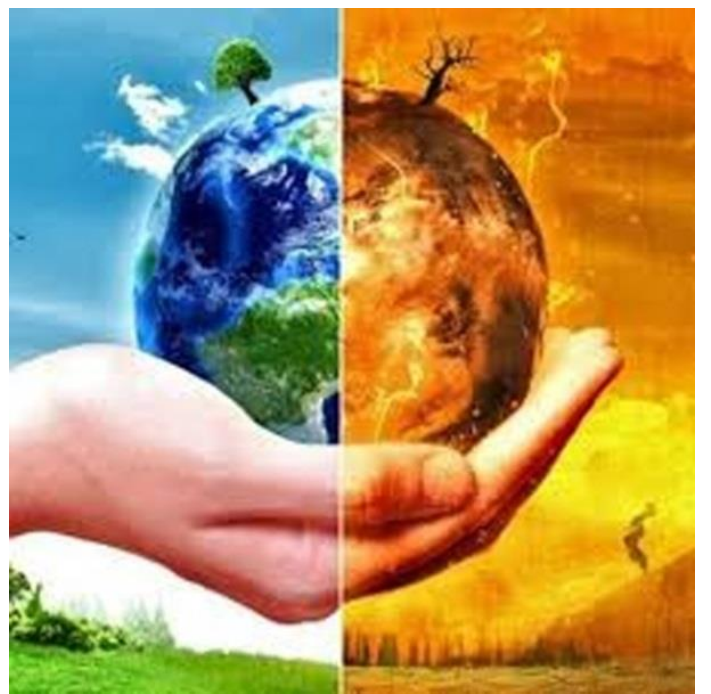

Şekil 8. Akıllı malzemelerin teorik ve pratik uygulamaları, sürdürülebilir bir gelecek yaşamı için yeni bağlantılar kurulmasında önemli bir katkı sağlamaktadır (African Wildlife Foundation (AWF), 2020).

Farklı sorular sorulmalıdır; akıllı malzemeleri mevcut sistemlere nasıl dâhil edilebileceğini sormak yerine, daha önce keşfedilmeyen şeyin ne olduğunu sorulmalıdır. Karşılaşılan her akıllı malzeme veya teknoloji, belirli fenomenolojik davranışlar açısından son derece spesifik olacak ve insanlara son teknoloji bilimini güncel bir insan ihtiyaçları bilgisi ile eşleştirmek için eşi görülmemiş bir fırsat verecektir. Kullanılmayan ve spesifik olmayan yapı materyallerini ve teknolojilerini sorgulanmaya başlanması ve işlevlerini ayırarak zenginleştirmek için fırsatlar aranması gerekmektedir. Bir sistem ne kadar ayrık olursa, o kadar doğrudan olmakta ve dolayısıyla verimli bir şekilde davranabilmektedir. Sürdürülebilirliğe yönelik yaklaşımları yeniden tanımlamak için yararlanılması gereken şey aslında malzemelerin kendisi bile değil, temel ilkeleridir. Ancak bu malzemeler sürdürülebilir çözümün basit antitezini temsil eden akıllı malzemeler yerine, sistemlerin daha basit hale gelmesini sağlayacak araçlar olarak düşünülmelidir.

Giderek artan çevre sorunlarına karşı mümkün olduğunca basit, yalın çözümler aranması ve farklı uzmanlıklarla beraber sorunların tartışılarak açığa kavuşturulup çözüm sağlanması gereklidir. Çalışmada değinildiği gibi günlük kullanıma yeni yeni giren akıllı malzemelerin teorik ve pratik uygulamaları, sürdürülebilir çevre sisteminin sağlanması yolunda ve yeni düşünce şekillerinin geliştirilip konu hakkında tartışmalar ile sürdürülebilir bir gelecek yaşamı için yeni bağlantılar kurulmasında önemli bir katkı sağlamaktadır.

Akıllı malzemeler ile birlikte işlevine uygun nitelik/enerji değişimi/dönüşümü oluşturacak biçimde tasarlanan yapı bileşenleri ve yapı elemanları yardımıyla, yaşam ömrü artan, enerji tüketimi azalan, yapı fiziği nitelikleri iyileşen, çevre yaşam kalitesini iyileştiren ve destekleyen, bakım giderleri daha da düşen, kendi enerjisini fazlasıyla üreten yapılar geleceğin mimarlık merceğinde kaçınılmaz ve vazgeçilmez olacaktır.

\section{Teşekkür ve Bilgi Notu}

Makalede, ulusal ve uluslararası araştırma ve yayın etiğine uyulmuştur. Çalışmada Etik Kurul izni gerekmemiştir. 


\section{Kaynaklar}

Abdullah, Y. S. ve Al-Alwan, H. A. S. (2019). Smart material systems and adaptiveness in architecture. Ain Shams Engineering Journal, 10(3), 623-638. doi:10.1016/j.asej.2019.02.002.

Addington, D. M. ve Schodek, D. L. (2005). Smart materials and technologies in architecture. Oxford: Architectural Press.

African Wildlife Foundation (AWF). (2020). Erişim Tarihi: 30.08 .2020 . https://nation.africa/kenya/blogs-opinion/opinion/we-have-a-responsibility-to-undo-the-harmwe-ve-done-the-world-171614, We have a responsibility to undo the harm we've done the world,

Alibaba. (2019). https://www.alibaba.com/product-detail/HOHO-2019-New-Smart-NanoPhotochromic_62084568094.html, HOHO 2019 New Smart Nano Photochromic Film VLT Transition Chameleon Tints For Car Window And Building Glass, Erişim Tarihi: 30.08.2020.

Anonim. (2017). Elektrokromik (Gerilim Ille Renk Değiştiren) Malzemeler, Yapısı ve Kullanım Yerleri Nelerdir? Erişim Adresi (30.08.2020): http://elektrikelektronikegitimi.blogspot.com/2017/05/voltaj-uygulandg-zaman-renkdegistiren.html

Anonim. (2020). Photovoltaics (PV) has become the cheapest source of electrical power in regions with a high potential. Erişim Adresi (30.08.2020): https://www.evwind.es/2020/02/02/photovoltaics-pv-has-become-the-cheapest-source-ofelectrical-power-in-regions-with-a-highpotential/73350\#: :text=More\%20than\%20100\%20countries\%20now,percent\%20of\%20global \%20electricity\%20demand

Bazilian, M., Onyeji, I., Liebreich, M., MacGill, I., Chase, J., Shah, J., ... Zhengrong, S. (2013). Reconsidering the economics of photovoltaic power. Renewable Energy, 53, 329-338. doi:10.1016/j.renene.2012.11.029

Cloudhem.

(2020).

Erişim

Adresi

(30.08.2020): https://www.cloudchem.com.cn/?gclid=EAlaIQobChMI_Ofc78Tb6QIVy5RCh2LiQTuEAAYASAAEg JHFvD_BwE

Diri, A. C., ve Gülçelik, L. (2018). The relationship between materials and esthetics in architecture: 5. international architectural design conference. Dubrovnik.

Elektrik elektronik egitimi. (2017,18 05). http://elektrikelektronikegitimi.blogspot.com/2017/05/voltaj-uygulandg-zaman-renkdegistiren.html, Elektrokromik (Gerilim Ile Renk Değiştiren) Malzemeler, Yapısı ve Kullanım Yerleri Nelerdir?, Erişim Tarihi: 30.08.2020.

Gautschi, G. (2002). Piezoelectric sensorics: force, strain, pressure, scceleration and scoustic emission sensors, materials and amplifiers. Berlin: Springer

Krautkrämer, J. ve Krautkrämer, H. (1990). Ultrasonic Testing of Materials. Berlin: Springer

Lyons, A. (2010). Materials for architects \& builders. Oxford: Architectural Press

Messenger, R. A. ve Ventre, J. (2013). Photovoltaic systems engineering. Florida: CRC Press

Monk, P. M., Mortimer, R. J. ve Rosseinky, D. R. (2007). Electrochromism and electrochromic devices. Cambridge: Cambridge University Press

Nikolov, N., ve Fox, J. (2014). Radiation-active surface design: The use of photocatalytic concrete enabling buildings to be active environmental remediators. Eco-Architecture V: Harmonisation between Architecture and Nature, 142, 199-204. doi: 10.2495/ARC140181

Okay, O. (2003). Polimerik Malzemelerin Bugünü ve Yarını. İstanbul Teknik Üniversitesi, Fen-Edebiyat Fakültesi, Kimya Bölümü. İstanbul 
Orhon, A. V. (2012). Akıllı Malzemelerin Mimarlıkta Kulanımı. Ege Mimarlık, 82, 18-21.

Orhon, A. V. (2013). Sürdürülebilir Mimaride Akıllı Malzeme Kullanımı. VIII. Uluslararası Sinan Sempozyumu Bildiri Kitabı, Edirne, 297-304.

Palz, W. (Ed). (2013). Solar power for the world: What you wanted to know about photovoltaics. In Solar Power for the World: Vol. 4. What you wanted to know about photovoltaics. Boca Raton, FL: CRC Press.

PCM. (2020). https://e-learning-re.blogspot.com/p/blog-page_14.html?view=snapshot, BASFMicronal's PCMs, Erişim Tarihi: 30.08.2020.

Ritter, A. (2007). Smart materials in architecture, interior architecture and design. Basel: Birkhäuser.

Sawin, J., L., Martinot, E., Sonntag-O’Brien, V., McCrone, A., Roussell, J., Barnes, D., \& Flavin, C. (2010). Renewables 2010 Global Status Report. Renewable Energy Policy Network for the 21st Century. Paris: REN21 Secretariat. Erişim Adresi (30.08.2020): https://www.ren21.net/Portals/0/documents/activities/gsr/REN21_GSR_2010_full_revised\%20 Sept2010.pdf

Shubbak, M. H. (2019). The technological system of production and innovation: The case of photovoltaic technology in China. Research Policy, 48(4), 993-1015. doi: 10.1016/j.respol.2018.10.003

Solaripedia. (2020a). Erişim Tarihi: 30.08.2020.

http://www.solaripedia.com/13/285/solar_ivy_uses_pvs_and_piezoelectrics.html, Solar Ivy Uses PVs and Piezoelectrics,

Solaripedia. (2020b). Erişim Tarihi: 30.08.2020.

https://www.solaripedia.com/13/285/3165/solar_ivy_closeup.html, Solar Ivy Uses PVs and Piezoelectrics,

Suze, K. (2016). To Make Smart Glass In Airplane Windows Could Have Widespread Uses. Erişim Adresi (30.08.2020): https://www.forbes.com/sites/sujatakundu/2016/08/31/electrochromicmaterials-used-to-make-smart-glass-in-aeroplane-windows-could-have-widespreaduses/\#317014017785

Swanson, R. M. (2009). Photovoltaics power up. Science, 324(5929), 891-892. doi: 10.1126/science.1169616

Şensan, S. Ö. (2019). Use of smart materıals in the desıgn of dynamı intellıgent surfaces. (Yüksek Lisans Tezi). The Graduate School of Social Sciences of Izmir University of Economics, İmir.

Ürkmez, B. (2019). Use of smart materıals in the desıgn of dynamıc intellıgent surfaces. (Yüksek Lisans Tezi). Istanbul Technical University, Architectural Design Computing Programme, İstanbul. 